\title{
An Ultrasensitive Silicon-Based Electrolyte-Gated Transistor for the Detection of Peanut Allergens
}

\author{
Donghoon Kim ${ }^{1,+}$, Bo Jin $\left.{ }^{1,2,+}{ }^{(}\right)$, Sol-A Kim ${ }^{3}{ }^{\circledR}$, Wonyeong Choi ${ }^{1}$, Seonghwan Shin ${ }^{1}$, Jiwon Park ${ }^{1}(\mathbb{D}$, \\ Won-Bo Shim ${ }^{4}$, Kihyun Kim ${ }^{5,6, * \mathbb{C}}$ and Jeong-Soo Lee ${ }^{1, *}$
}

1 Department of Electrical Engineering, Pohang University of Science and Technology (POSTECH), Pohang 37673, Korea; kdong620@postech.ac.kr (D.K.); shengzhi86@postech.ac.kr (B.J.); pathfinder@postech.ac.kr (W.C.); ssh3290a@postech.ac.kr (S.S.); jwpark78@postech.ac.kr (J.P.)

2 Research and Development Department, Innovative General Electronic Sensor Technology Co., Itd. (IGEST), Pohang 37673, Korea

3 Division of Applied Life Science, Graduate School, Gyeongsang National University, Jinju 52828, Korea; thfdk718@naver.com

4 Department of Food Science and Technology, Gyeongsang National University, Jinju 52828, Korea; wbshim@gnu.ac.kr

5 Division of Electronics Engineering, Jeonbuk National University, Jeonju 54896, Korea

6 Future Semiconductor Convergence Technology Research Center and ICT Convergence Research Center, Jeonbuk National University, Jeonju 54896, Korea

* Correspondence: kihyun.kim@jbnu.ac.kr (K.K.); ljs6951@postech.ac.kr (J.-S.L.)

+ Co-first author, these authors contributed equally to this work.

check for updates

Citation: Kim, D.; Jin, B.; Kim, S.-A.; Choi, W.; Shin, S.; Park, J.;

Shim, W.-B.; Kim, K.; Lee, J.-S. An

Ultrasensitive Silicon-Based

Electrolyte-Gated Transistor for the

Detection of Peanut Allergens.

Biosensors 2022, 12, 24. https://

doi.org/10.3390/bios12010024

Received: 3 December 2021

Accepted: 31 December 2021

Published: 4 January 2022

Publisher's Note: MDPI stays neutral with regard to jurisdictional claims in published maps and institutional affiliations.

Copyright: (C) 2022 by the authors. Licensee MDPI, Basel, Switzerland. This article is an open access article distributed under the terms and conditions of the Creative Commons Attribution (CC BY) license (https:// creativecommons.org/licenses/by/ $4.0 /)$.

\begin{abstract}
The highly sensitive detection of peanut allergens (PAs) using silicon-based electrolytegated transistors (Si-EGTs) was demonstrated. The Si-EGT was made using a top-down technique. The fabricated Si-EGT showed excellent intrinsic electrical characteristics, including a low threshold voltage of $0.7 \mathrm{~V}$, low subthreshold swing of $<70 \mathrm{mV} / \mathrm{dec}$, and low gate leakage of $<10 \mathrm{pA}$. Surface functionalization and immobilization of antibodies were performed for the selective detection of PAs. The voltage-related sensitivity $\left(S_{V}\right)$ showed a constant behavior from the subthreshold regime to the linear regime. The current-related sensitivity $\left(S_{I}\right)$ was high in the subthreshold regime and then significantly decreased as the drain current increased. The limit of detection (LOD) was calculated to be as low as $25 \mathrm{pg} / \mathrm{mL}$ based on $S_{I}$ characteristics, which is the lowest value reported to date in the literature for various sensor methodologies. The Si-EGT showed selective detection of PA through a non-specific control test. These results confirm that Si-EGT is a high-sensitivity and low-power biosensor for PA detection.
\end{abstract}

Keywords: BioFET; biosensor; electrolyte gate; limit of detection; peanut allergen

\section{Introduction}

Peanuts are a primary source of IgE-mediated food allergies, along with tree nuts, milk, eggs, soybeans, and fish [1,2]. Peanuts can be a particularly severe threat to sensitive people because they can cause life-threatening anaphylactic shock [3]. Additionally, peanut allergies persist into adulthood in $75 \%$ to $80 \%$ of cases [4]. Peanut allergens (PAs) constitute approximately $85 \%$ of the total peanut protein content, and PA is classified as Arachis hypogaea 1 (Ara h1) to Ara h13 [5,6]. Ara h1 and Ara h3 belong to the cupin superfamily and are the two main allergens that cause allergic reactions in up to $35 \%$ to $95 \%$ of patients [7]. An allergic person is strictly advised to avoid the consumption of peanut-related products because even a trace of PA can trigger an allergic reaction.

The enzyme-linked immunosorbent assay (ELISA) is the most commonly used method for diagnosing PAs. The ELISA has been used as a versatile platform with high reliability and sensitivity, and it has been demonstrated to detect allergenic proteins in peanuts [8-10]. 
However, this technique is typically very time-consuming and requires expensive laboratory equipment and trained experts. Alternative approaches have been reported, including polymerase chain reaction (PCR), real-time PCR, and PCR-ELISA [11-14]. These methods detect the peanut ingredients in food using PA DNA amplification. The limit of detection (LOD) is typically a few tenths of a DNA copy per reaction $(\sim 0.1 \mathrm{~mL})$ [15]. However, these sensitive label-based PCR techniques have drawbacks similar to those of ELISA. Additionally, the quantitative detection of PAs is challenging based on the lack of a direct correlation between DNA concentrations and allergen concentrations.

To overcome the problems associated with ELISA and PCR methodologies, biologically active field-effect transistors (BioFETs) using nanomaterials or nanostructures have been investigated [16,17]. Such BioFETs rely on the label-free detection of electrical signals modulated by binding target biomolecules to a functionalized sensing surface. Several applications of BioFETs have been demonstrated to detect various biomolecules with higher normalized sensitivity and enhanced LODs [18-21]. However, the sensing current itself is very small as a result of the use of a nanoscale channel, which requires more complex and expensive signal-processing integrated circuits.

Recently, an electrolyte-gated FET (EGT) was introduced [22-27]. The large area of the gate electrode in an EGT can be utilized as a functionalization surface to increase the binding probability of biomolecules, thereby increasing the absolute sensing current.

Here, we demonstrated the ultrasensitive and label-free detection of Ara h1 and Ara h3 using an Si-EGT. Our devices were fabricated using micro- and nano-semiconductor processing techniques. Surface functionalization and immobilization of antibodies were performed for the selective detection of PAs. Voltage- or current-related sensitivities depending on the operation regime were investigated to achieve higher sensitivity and lower power consumption. Improved sensitivities and LOD were achieved in a Si-based EGT operation. Non-specific binding tests were also conducted.

\section{Materials and Methods}

\subsection{Fabrication of Si-EGTs}

Figure 1 shows the fabrication flow of an Si-EGT using a top-down process. An 8-inch silicon-on-insulator wafer (boron-doped, $10 \Omega \cdot \mathrm{cm}$ ) with a $100 \mathrm{~nm}$ top Si layer and $400 \mathrm{~nm}$ buried oxide layer was used as a starting material. The active region (composed of the source, drain, and channel) was defined using deep ultraviolet lithography and an inductively coupled plasma reactive ion etching process. An arsenic dopant with a dose of $2 \times 10^{15} / \mathrm{cm}^{2}$ was implanted onto the substrate, excluding the channel region. Rapid thermal annealing was then conducted at $1000{ }^{\circ} \mathrm{C}$ for $20 \mathrm{~s}$. Next, thermal wet oxidation was applied to grow silicon oxide $(5 \mathrm{~nm})$ as a gate insulator. A 50/500 nm Ti/Ag layer was formed using an e-beam evaporator and conventional lift-off process for the contacts, gate electrode, and transmission lines. Finally, an SU-8 passivation layer was formed on the entire surface using photolithography, excluding the gate electrode and channel regions which are supposed to be exposed to the sample solution. The surface areas of the gate electrode and channel were $300 \mu \mathrm{m} \times 300 \mu \mathrm{m}$ and $10 \mu \mathrm{m} \times 10 \mu \mathrm{m}$, respectively. 
(a)

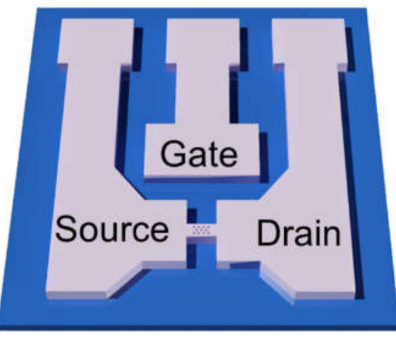

(1) Active region formation

(d)

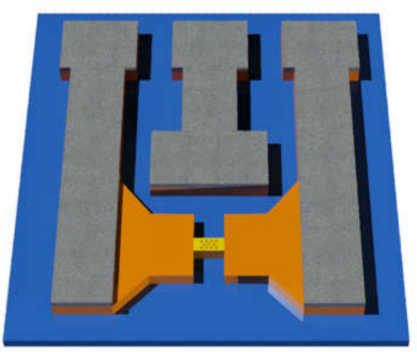

(4) Metal deposition (b)

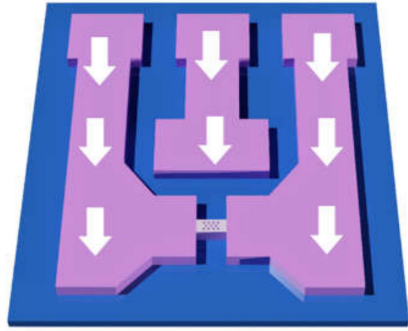

(2) Ion implantation

(e)

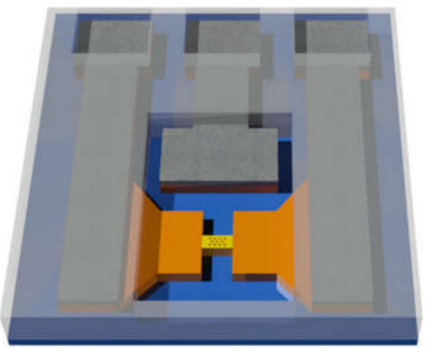

(5) SU-8 Passivation (c)

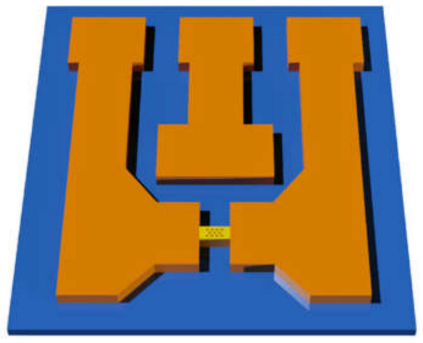

(3) Gate oxidation

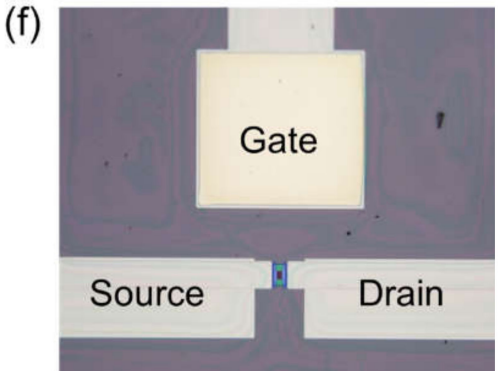

Figure 1. (a-e) Schematics of fabrication flow and (f) an optical image of the top view of the fabricated Si-EGT.

\subsection{Preparation of PAs and Their Antibodies}

Monoclonal antibody (Mab) was produced from mice immunized with a thermalstable soluble protein (TSSP) of peanut. To extract TSSP, including Ara h1 and h3 [28], $1 \mathrm{~g}$ of roasted peanut was crushed finely, followed by mixing with $10 \mathrm{~mL}$ of carbonate buffer $(0.1 \mathrm{M}, \mathrm{pH}$ 9.6). The mixture was placed in boiling water for $15 \mathrm{~min}$ and then cooled to room temperature. The mixture was then centrifuged at $4{ }^{\circ} \mathrm{C}$ for $15 \mathrm{~min}$ at $3000 \mathrm{rpm}$. After filtering the supernatant containing TSSP through Whatman No. 1 filter paper, dialysis in $1 \times$ phosphate-buffered saline (PBS) was performed twice daily for $3 \mathrm{~d}$. The extracted TSSP was used as an immunogen. IgG Mab was developed through cell fusion and cloning $[29,30]$. Figure 2 shows the Western blot analysis. It confirmed that the antibody was specific to PA without cross-reactivity with other food allergens such as almonds, cashew nuts, and red beans. An antigen-binding fragment (Fab), which is a region on Mab binding to antigens, was generated via papain treatment [31]. After purification using a protein $\mathrm{G}$ column, the Fab was used as a receptor to detect PA.

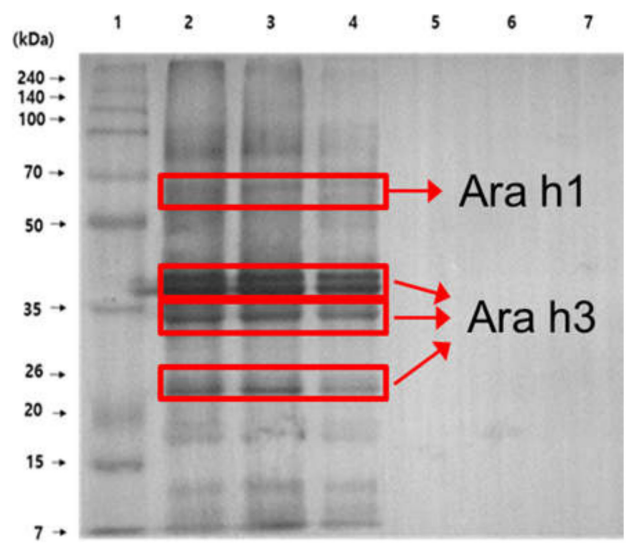

Figure 2. Western blot results. Lane 1: marker; lane 2: roasting peanut; lane 3: boiled peanut; lane 4: peanut butter; lane 5: almond; lane 6: cashew nut; lane 7: red bean. 


\subsection{Immobilization of PA Antibodies on Si-EGT}

A series of chemical surface treatments were conducted to attach Fab to the sensing surface. First, the devices were rinsed in ethanol and distilled water (DIW) for cleaning, followed by UV/ozone treatment for $1.5 \mathrm{~min}$. Then, 3-aminopropyl-triethoxysilane (APTES) vaporization was performed for $1 \mathrm{~min}$ at $50^{\circ} \mathrm{C}$ to cover the surface with an amine group $\left(-\mathrm{NH}_{2}\right)$. Next, the device was immersed in a $1 \times \mathrm{PBS}$ solution with $2.5 \%$ glutaraldehyde for $90 \mathrm{~min}$ to form an aldehyde terminal (-CHO) on its surfaces. Finally, the device was exposed to a PA antibody solution $(200 \mu \mathrm{g} / \mathrm{mL})$ for $1 \mathrm{~h}$.

The surface of the antibody-functionalized Ag electrode was analyzed using atomic force microscopy (AFM, VEECO, New York, NY, USA). As shown in Figure 3a,b, the average roughness and standard deviation were 6 and $9.6 \mathrm{~nm}$ for the bare surface, and $10.3 \mathrm{~nm}$ and $15.4 \mathrm{~nm}$ for the functionalized $\mathrm{Ag}$ surface, respectively. The increased surface roughness indicates that the PA antibody was successfully immobilized on the Ag surface.

(a)

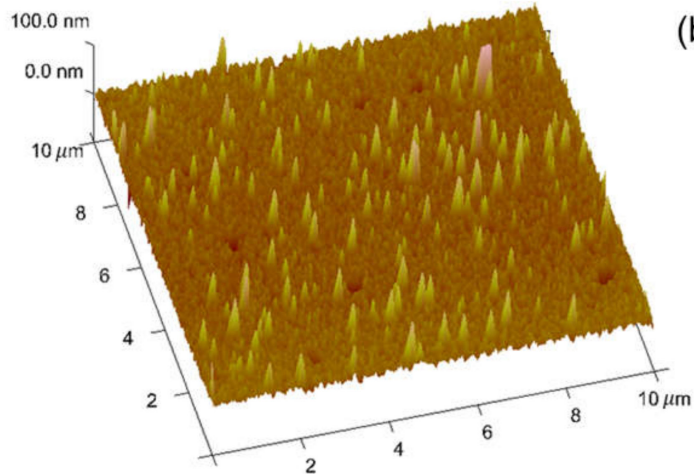

(b)

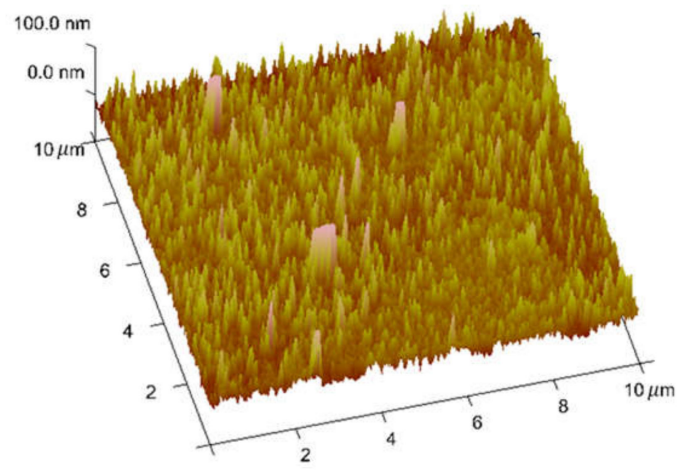

Figure 3. AFM image analysis of the (a) bare and (b) antibody-immobilized Ag gate electrode.

\subsection{Electrical Measurement System}

The electrical characteristics and PA sensing responses were characterized using a semiconductor parameter analyzer (Keithley 4200SCS, Tektronix, Beavern, OR, USA) at room temperature. The transfer curve (drain current $I_{D}$ vs. gate voltage $V_{G}$ ) was measured as a function of $V_{G}$ at $V_{D}=0.1 \mathrm{~V}$ in $20 \mu \mathrm{L}$ of $0.01 \times \mathrm{PBS}$ solution. For quantitative PA analyses, a PA solution using the extracted TSSP in a $1 \times$ PBS solution was prepared with a concentration in the range of $10 \mathrm{pg} / \mathrm{mL}$ to $1 \mathrm{mg} / \mathrm{mL}$. After the initial transfer curve was characterized, the device was exposed to $20 \mu \mathrm{L}$ of PA solution for $20 \mathrm{~min}$, followed by a DIW rinse. Next, $20 \mu \mathrm{L}$ of $0.01 \times$ PBS solution was dropped onto the device and another measurement was performed to analyze the PA sensing responses.

\section{Results}

\subsection{Intrinsic Electrical Characteristics}

Figure 4a shows the transfer curves $\left(\log \left(I_{D}\right)\right.$ vs. $\left.V_{G}\right)$ and output curves $\left(I_{D}\right.$ vs. $\left.V_{D}\right)$ of the as-fabricated Si-EGTs prior to surface functionalization. These curves indicate that the device was a typical long-channel n-type FET with a threshold voltage $\left(V_{T H}\right)$ of $\sim 0.7 \mathrm{~V}$. A subthreshold swing $\left(=\mathrm{d} V_{G} / \mathrm{d} \log \left(I_{D}\right)\right)$ of $\sim 70 \mathrm{mV} / \mathrm{dec}$, gate leakage current of $<10 \mathrm{pA}$, and on/off current ratio of $\sim 10^{7}$ were achieved. The low gate leakage current indirectly confirms the high quality of the gate oxide and successful formation of SU-8 passivation. $I_{D}$ is exponentially proportional to $V_{G}$ in the subthreshold regime $\left(V_{G}<V_{T H}\right)$ and has a linear dependency in the linear regime $\left(V_{G}>V_{T H}\right)$, as follows [32]:

$$
\begin{gathered}
I_{D \_S U B} \sim \exp \left[\frac{q\left(V_{G}-V_{T H}\right)}{k T}\right], \\
I_{D \_L I N} \sim\left(V_{G}-V_{T H}\right),
\end{gathered}
$$


where $q$ is the electron charge, $k$ is the Boltzmann constant, $T$ is the temperature, and $I_{D \_} S U B$ and $I_{D_{-} L I N}$ are the drain currents in the subthreshold and linear regimes, respectively.
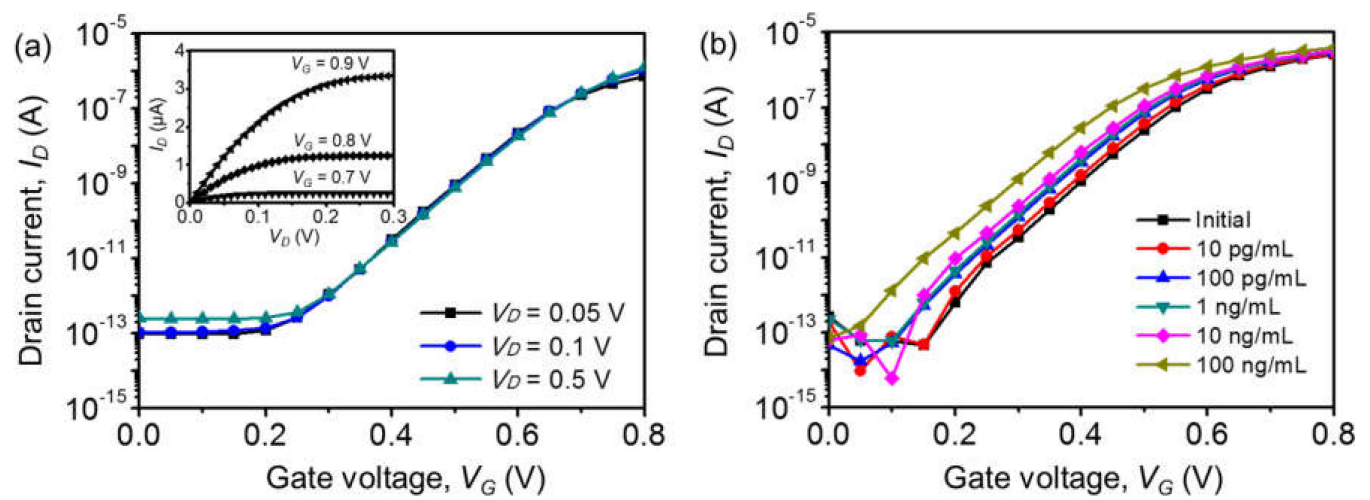

Figure 4. (a) Log-scaled $I_{D}-V_{G}$ transfer characteristics of the fabricated Si-EGT for various $V_{D}$. Inset: $I_{D}-V_{D}$ output characteristics. (b) Log-scaled $I_{D^{-}} V_{G}$ for varying [PA]s of $10 \mathrm{pg} / \mathrm{mL}$ to $100 \mathrm{ng} / \mathrm{mL}$.

\subsection{Sensing Responses for PA Detection}

Figure $4 \mathrm{~b}$ shows representative transfer curves for the Si-EGT with various PA concentrations ([PA]s) from the initial PBS (no PA) up to $100 \mathrm{ng} / \mathrm{mL}$. The curve shifts in the negative $V_{G}$ direction as [PA] increases.

The voltage-related sensitivity $\left(S_{V}\right)$ and current-related sensitivity $\left(S_{I}\right)$ are defined as follows $[33,34]$ :

$$
\begin{aligned}
& S_{V}=V_{G, A b}-V_{G, A b_{-} P A}, \\
& S_{I}=\frac{I_{D, A b}-I_{D, A b \_P A}}{I_{D, A b}},
\end{aligned}
$$

where $V_{G, A b}$ and $V_{G, A b \_} P A$ are the gate voltages after antibody immobilization and antibodyPA reactions at a fixed $I_{D}$, respectively, and $I_{D, A b}$ and $I_{D, A b} P A$ are the drain currents after antibody immobilization and the antibody-PA reactions at a fixed $I_{D}$, respectively.

Figure 5a,b show the calculated $S_{V}$ and $S_{I}$ as functions of $I_{D, A b}$ from the subthreshold to the linear regime. $S_{V}$ is almost constant, independent of $I_{D}$. However, $S_{I}$ decreases significantly as the device is operated from the subthreshold to linear regimes by increasing $V_{G}$. According to Equation (1), $I_{D}$ increases exponentially with a linear change in $V_{G}$ in the subthreshold regime. For example, with a PA of $100 \mathrm{ng} / \mathrm{mL}$, the $S_{I}$ value is as high as $2000 \%$ at $I_{D, A b}=100 \mathrm{pA}$ (subthreshold regime), which is almost 200 times higher than $S_{I}$ at $I_{D, A b}=1 \mu \mathrm{A}$ (linear regime). Therefore, the device should be operated in the subthreshold regime to achieve high sensitivity and low power consumption.
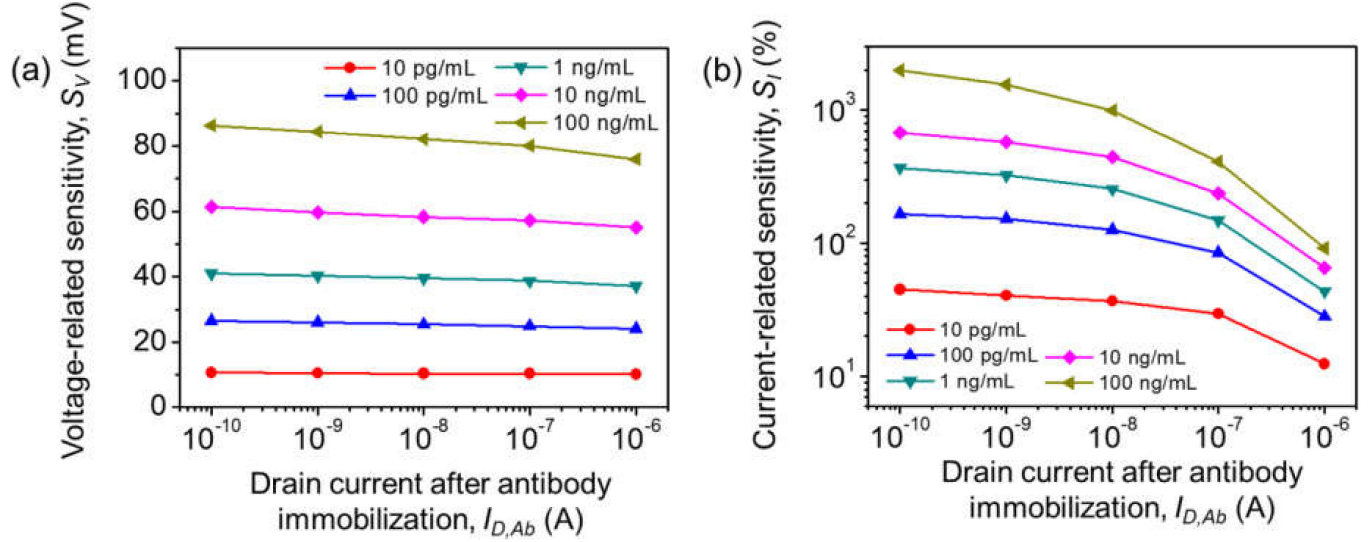

Figure 5. (a) Average voltage-related sensitivity $S_{V}$ and (b) average current-related sensitivity $S_{I}$ vs. $I_{D, A b}$ of various $[\mathrm{PA}] \mathrm{s}$. 


\subsection{Sensitivity, $L O D$, and Selectivity}

Figure $6 \mathrm{a}, \mathrm{b}$ show $S_{V}$ and $S_{I}$ vs. the logarithm of the $[\mathrm{PA}]$ at $I_{D, A b}=100 \mathrm{pA}$. A logistic calibration curve was used to determine the relationship between sensor responses and antigen concentrations [35-37]. The curves from the fit were $S_{V}=130 \times[\mathrm{PA}]^{0.34} /(2.06 \times$ $\left.10^{-3}+[\mathrm{PA}]^{0.34}\right)$ and $S_{I}=7100 \times[\mathrm{PA}]^{0.42} /\left(3.33 \times 10^{-3}+[\mathrm{PA}]^{0.42}\right)$. The dynamic range was more than four orders of magnitude from $100 \mathrm{pg} / \mathrm{mL}$ to $1 \mu \mathrm{g} / \mathrm{mL}$ of [PA].

(a)

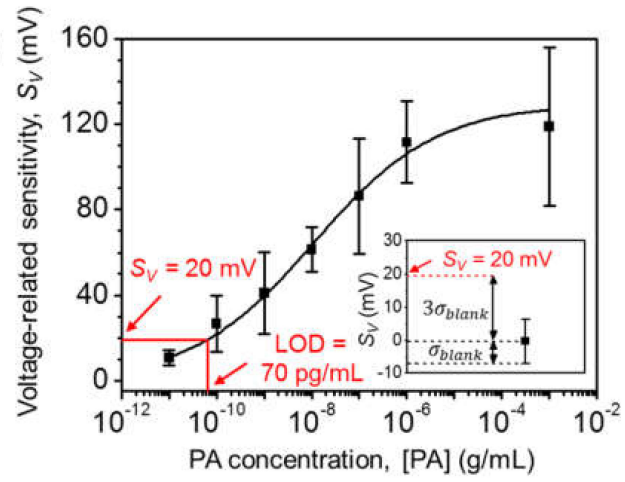

(b)

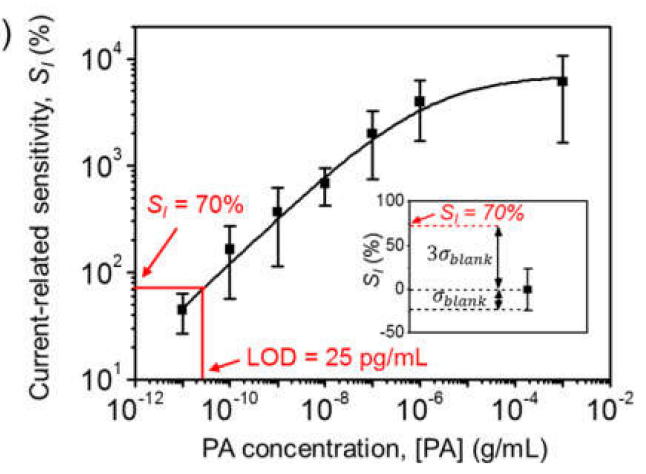

Figure 6. [PA] vs. (a) $S_{V}$ and (b) $S_{I}$ at $I_{D, A b}=100 \mathrm{pA}$. The solid lines which are showed in the figures are logistic fitted lines. Inset: $S_{V}, S_{I}$ of blank replicates $\left(1 \times\right.$ PBS solution with no PAs), and $S_{V}, S_{I}$ at the LOD using the three-sigma method.

The LOD was calculated using the three-sigma method [38,39]. The standard deviations from the blank replicate $(1 \times$ PBS solution without PA) were as low as $7 \mathrm{mV}$ for $S_{V}$ and $23 \%$ for $S_{I}$. The extracted LODs for $S_{V}$ and $S_{I}$ were as low as $70 \mathrm{pg} / \mathrm{mL}$ and $25 \mathrm{pg} / \mathrm{mL}$, respectively. Table 1 summarizes the LODs of various PA sensors in the literature, including ELISA [9], heat transfer methods [40], surface-enhanced Raman spectroscopy (SERS) [41], and resistors [42,43]. The LOD for our Si-EGT is almost ten times lower than those in previous reports.

Table 1. LOD comparison between various PA sensors.

\begin{tabular}{ccccc}
\hline Sensor Type & PA Type & Dynamic Range & LOD & Ref. \\
\hline ELISA & Ara h3 & $240 \mathrm{pg} / \mathrm{mL}-125 \mathrm{ng} / \mathrm{mL}$ & $240 \mathrm{pg} / \mathrm{mL}$ & {$[9]$} \\
\hline Heat transfer method & Ara h1 & $315 \mathrm{ng} / \mathrm{mL}-3 \mu \mathrm{g} / \mathrm{mL}$ & $189 \mathrm{ng} / \mathrm{mL}$ & {$[40]$} \\
\hline SERS & Ara h1 & $90 \mathrm{ng} / \mathrm{mL}-36 \mu \mathrm{g} / \mathrm{mL}$ & $90 \mathrm{ng} / \mathrm{mL}$ & {$[41]$} \\
\hline $\begin{array}{c}\text { Two electrodes } \\
\text { resistor }\end{array}$ & Ara h1 & $12.6 \mathrm{ng} / \mathrm{mL}-2 \mu \mathrm{gg} / \mathrm{mL}$ & $3.8 \mathrm{ng} / \mathrm{mL}$ & {$[42]$} \\
\hline $\begin{array}{c}\text { Carbon nanotube } \\
\text { resistor }\end{array}$ & Ara h1 & $1 \mathrm{ng} / \mathrm{mL}-100 \mu \mathrm{g} / \mathrm{mL}$ & $1 \mathrm{ng} / \mathrm{mL}$ & {$[43]$} \\
\hline Si-EGT & Ara h1, h3 & $100 \mathrm{pg} / \mathrm{mL}-1 \mu \mathrm{g} / \mathrm{mL}$ & $25 \mathrm{pg} / \mathrm{mL}$ & This work \\
\hline
\end{tabular}

Figure 7 shows non-specific control experiments for confirming PA selectivity. The immobilized devices were exposed to cardiac troponin I (cTnI), streptavidin, and avidin. The $S_{I}$ values from relatively high-concentration biomolecules were far below the LOD level, indicating that the sensitivity stems from specific PA binding. Additionally, $S_{I}$ was almost zero with no surface functionalization upon exposure to $1 \mu \mathrm{g} / \mathrm{mL}$ of PA, suggesting that the PA antibodies were successfully immobilized. 


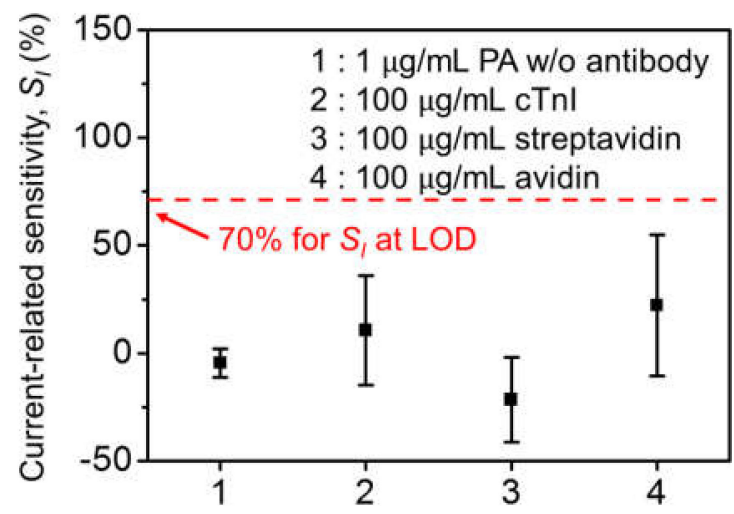

Figure 7. Selectivity test with $1 \mu \mathrm{g} / \mathrm{mL}$ PA without surface functionalization, $100 \mu \mathrm{g} / \mathrm{mL} \mathrm{cTnI}$, streptavidin, and avidin with surface functionalization at $I_{D, A b}=100 \mathrm{pA}$.

\subsection{Detection Principle of Si-EGTs}

Binding events on a sensing surface are described using various methods [23-25,44]. Among them, the presence of a dipole layer has been typically utilized to explain the detection principle of EGT devices [23-25]. The magnitude and direction of the dipole layer are largely dependent on the type of antibody-antigen conjugate and its density on the surface. The dipole potential $\left(V_{D P}\right)$ generated by an antibody-antigen reaction is expressed as [25]:

$$
V_{D P}=\frac{N_{A b_{-} A g} P_{D P}}{\varepsilon_{D P}}
$$

where $N_{A b \_A g}$ is the areal density of antibody-antigen conjugates, $P_{D P}$ is the dipole moment, and $\varepsilon_{D P}$ is the dielectric constant of the dipole layer. Because $P_{D P}$ and $\varepsilon_{D P}$ are intrinsic characteristics of the conjugates and are the same on both gate electrode and the channel, $V_{D P}$ has a proportional relationship with $N_{A b \_} A g$.

To compare the induced $V_{D P}$ on the gate electrode $\left(V_{D P, G T}\right)$ and channel $\left(V_{D P, C H}\right)$, $N_{A b \_A g}$ can be estimated using a gold nanoparticle (AuNP)-conjugated antigen. Based on the limited availability of AuNP-conjugated PA, streptavidin and AuNP-conjugated biotin were used alternatively. After the same functionalization treatment, $1 \mathrm{mg} / \mathrm{mL}$ of streptavidin solution was exposed for $2 \mathrm{~h}$, followed by a reaction with AuNP-conjugated biotin for $2 \mathrm{~h}$. Figure 8 shows the scanning electron microscopy (SEM) images of the immobilized AuNPs on the channel and the gate electrode. AuNPs were mainly attached along the grain boundary of the gate electrode. The areal density of AuNPs on the gate electrode was 5 to 10 times higher than that on the channel. This result indicates that $V_{D P, G T}$ is the dominant component affecting the sensing characteristics of Si-EGT.

(a)

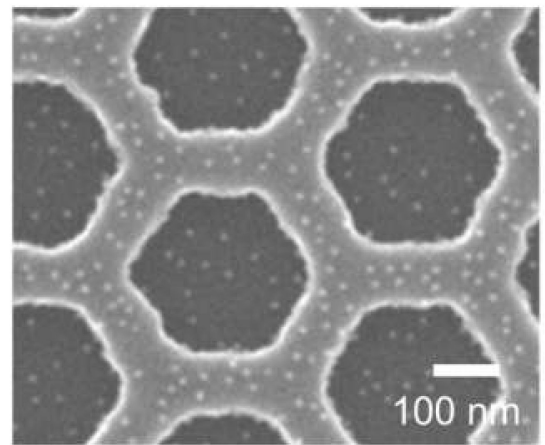

(b)

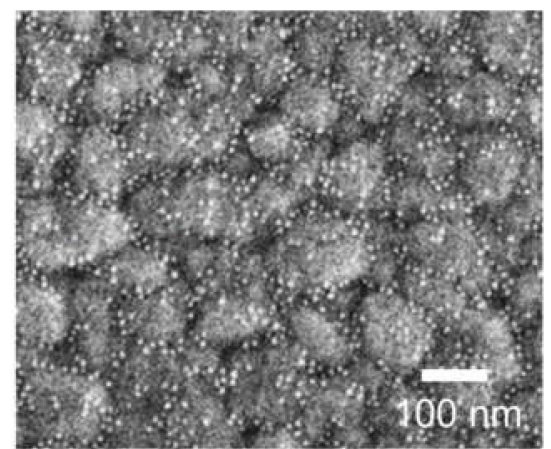

Figure 8. SEM images of (a) the channel and (b) the gate electrode with the immobilization of AuNPs (diameter: $10 \mathrm{~nm}$ ).

Figure 9 shows an energy band diagram for the Si-EGT after antibody immobilization and antibody-PA reaction. This diagram explains several sensing characteristics with two representative operation points: the flat band condition $\left(V_{G}=V_{F B}, \varphi_{S}=0\right)$ and threshold 
voltage condition $\left(V_{G}=V_{T H}, \varphi_{S}=2 \varphi_{F}\right)$. The dipole potential on the gate electrode causes a change in the effective work function of the gate metal, which is relevant to the threshold voltage $\left(V_{T H}\right)$ [23-25].

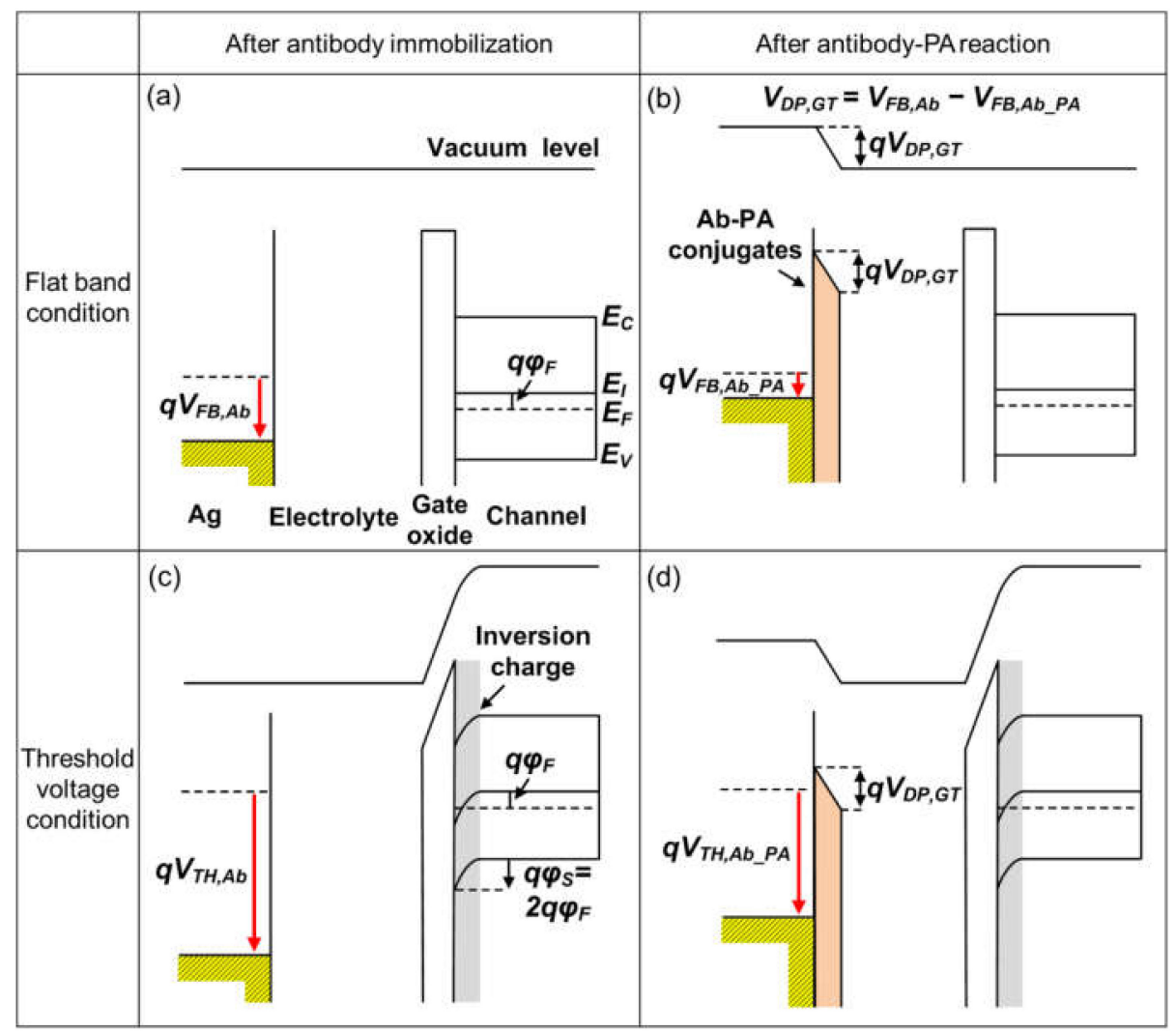

Figure 9. (a-d) Energy band diagrams of EGTs after antibody immobilization and after antibody-PA reactions under flat band conditions $\left(V_{G}=V_{F B}, \varphi_{S}=0\right)$ and threshold voltage conditions $\left(V_{G}=V_{T H}\right.$, $\left.\varphi_{S}=2 \varphi_{F}\right)$.

When a PA solution is dropped onto the antibody-immobilized Si-EGT, the antibodyPA conjugate forms a dipole layer on the gate surface where the electric field points toward the gate electrode, as shown in Figure $9 \mathrm{~b}, \mathrm{~d}$. The potential drop $\left(V_{D P, G T}\right)$ across the dipole decreases the work function of the gate electrode, followed by $V_{F B, A b_{-} P A}=V_{F B, A b}-V_{D P, G T}$. Therefore, an increase in [PA] requires a less positive $V_{G}$ to flow the same drain current, or it results in the reduction of $V_{T H}$.

\section{Conclusions}

We demonstrated the highly sensitive detection of PAs using Si-based electrolyte-gated FET biosensors. The fabricated devices showed excellent intrinsic characteristics, including a low $V_{\mathrm{TH}}$ of $\sim 0.7 \mathrm{~V}$, low subthreshold swing of $\sim 70 \mathrm{mV} / \mathrm{dec}$, low gate leakage current of $<10 \mathrm{pA}$, and high $I_{O N} I_{\text {OFF }}$ ratio of $\sim 10^{7}$. The voltage-related and current-related sensitivities depending on the operation regimes were investigated to achieve higher sensitivity and low power consumption. The current-related sensitivity decreases exponentially as $I_{D}$ increases from the subthreshold regime to the linear regime. The voltage-related sensitivity is almost constant with the gate voltage and increases by approximately $90 \mathrm{mV}$ for $[\mathrm{PA}]=100 \mathrm{ng} / \mathrm{mL}$. The calculated LOD is $25 \mathrm{pg} / \mathrm{mL}$. High specificity was also confirmed through non-specific binding tests. These results suggest that Si-EGT is very promising for identifying PAs and screening PAs in food samples.

Author Contributions: Conceptualization, D.K. and B.J.; methodology, D.K., S.-A.K. and K.K.; validation, W.C. and W.-B.S.; investigation, S.S. and J.P.; data curation, S.S. and J.P.; writing-original draft 
preparation, D.K., B.J., K.K. and J.-S.L.; writing-review and editing, D.K. and J.-S.L.; supervision, K.K. and J.-S.L. All authors have read and agreed to the published version of the manuscript.

Funding: This work was supported by Food, Agriculture, Forestry, and Fisheries (IPET) through the Animal Disease Management Technology Development Program, which is funded by the Ministry of Agriculture, Food, and Rural Affairs (MAFRA) (120091-02-1-CG000), and by the MSIT (Ministry of Science and ICT), Korea, under the "Nano·Material Technology Development Program" (20090082580) supervised by the NRF (National Research Foundation of Korea).

Conflicts of Interest: The authors declare no conflict of interest.

\section{References}

1. Sicherer, S.H.; Sampson, H.A. Food allergy: A review and update on epidemiology, pathogenesis, diagnosis, prevention, and management. J. Allergy Clin. Immunol. 2018, 141, 41-58. [CrossRef]

2. Lieberman, J.A.; Glaumann, S.; Batelson, S.; Borres, M.P.; Sampson, H.A.; Nilsson, C. The utility of peanut components in the diagnosis of IgE-mediated peanut allergy among distinct populations. J. Allergy Clin. Immunol. 2013, 1, 75-82. [CrossRef]

3. Lieberman, J.A.; Gupta, R.S.; Knibb, R.C.; Haselkorn, T.; Tilles, S.; Mack, D.P.; Pouessel, G. The Global Burden of Illness of Peanut Allergy: A Comprehensive Literature Review. Allergy 2020, 76, 1367-1384. [CrossRef]

4. Bégin, P.; Paradis, L.; Paradis, J.; Picard, M.; Roches, A.D. Natural resolution of peanut allergy: A 12-year longitudinal follow-up study. J. Allergy Clin. Immunol. 2013, 1, 528-530. [CrossRef]

5. Hebling, C.M.; Ross, M.M.; Callahan, J.H.; McFarland, M.A. Size-Selective Fractionation and Visual Mapping of Allergen Protein Chemistry in Arachis hypogaea. J. Proteome Res. 2012, 11, 5384-5395. [CrossRef]

6. Bublin, M.; Breiteneder, H. Cross-reactivity of peanut allergens. Curr. Allergy Asthme Rep. 2014, 14, 426. [CrossRef]

7. Scurlock, A.M.; Burks, A.W. Peanut allergenicity. Ann. Allergy Asthma Immunol. 2004, 93, S12-S18. [CrossRef]

8. Montserrat, M.; Sanz, D.; Juan, T.; Herrero, A.; Sanchez, L.; Calvo, M.; Perez, M.D. Detection of peanut (Arachis hypogaea) allergens in processed foods by immunoassay: Influence of selected target protein and ELISA format applied. Food Control. 2015, 54, 300-307. [CrossRef]

9. Weng, X.; Gaur, G.; Neethirajan, S. Rapid Detection of Food Allergens by Microfluidics ELISA-Based Optical Sensor. Biosensors 2016, 6, 24. [CrossRef]

10. Pandey, A.K.; Varshney, R.K.; Sudini, H.K.; Pandey, M.K. An Improved Enzyme-Linked Immunosorbent Assay (ELISA) Based Protocol Using Seeds for Detection of Five Major Peanut Allergens Ara h 1, Ara h 2, Ara h 3, Ara h 6, and Ara h 8. Front. Nutr. 2019, 6, 68. [CrossRef]

11. Oliver, S.; Stefan, V. Development of a Real-Time PCR and a Sandwich ELISA for Detection of Potentially Allergenic Trace Amounts of Peanut (Arachis hypogaea) in Processed Foods. J. Agric. Food Chem. 2004, 52, 3754-3760.

12. Inés, M.L.-C.; Silvia, d.l.C.; Nicolette, P.; Isabel, G.; Teresa, G.; Rosario, M. Development of a real time PCR assay for detection of allergenic trace amounts of peanut (Arachis hypogaea) in processed foods. Food Control. 2013, 30, 480-490.

13. Zhang, W.-J.; Cai, Q.; Guan, X.; Chen, Q. Detection of peanut (Arachis hypogaea) allergen by Real-time PCR method with internal amplification control. Food Chem. 2015, 174, 547-552. [CrossRef]

14. Puente-Lelievre, C.; Eischeid, A.C. Development and evaluation of a real-time PCR multiplex assay for the detection of allergenic peanut using chloroplast DNA markers. J. Agric. Food Chem. 2018, 66, 8623-8629. [CrossRef]

15. Forootan, A.; Sjöback, R.; Björkman, J.; Sjögreen, B.; Linz, L.; Kubista, M. Methods to determine limit of detection and limit of quantification in quantitative real-time PCR (qPCR). Biomol. Detec. Quantif. 2017, 12, 1-6. [CrossRef]

16. Cui, Y.; Wei, W.; Park, H.; Lieber, C.M. Nanowire nanosensors for highly sensitive and selective detection of biological and chemical species. Science 2001, 293, 1289-1292. [CrossRef]

17. Ding, B.; Wang, M.; Wang, X.; Yu, J.; Sun, G. Electrospun nanomaterials for ultrasensitive sensors. Mater. Today 2010, 13, 16-27. [CrossRef]

18. Kanai, Y.; Ohmuro-Matsuyama, Y.; Tanioku, M.; Ushiba, S.; Ono, T.; Inoue, K.; Kitaguchi, T.; Kimura, M.; Ueda, H.; Matsumoto, K. Graphene field effect transistor-based immunosensor for ultrasensitive noncompetitive detection of small antigens. ACS Sens. 2020, 5, 24-28. [CrossRef]

19. Stern, E.; Klemic, J.F.; Routenberg, D.A.; Wyrembak, P.N.; Turner-Evans, D.B.; Hamilton, A.D.; LaVan, D.A.; Fahmy, T.M.; Leed, M.A. Label-free immunodetection with CMOS-compatible semiconducting nanowire. Nature 2007, 445, 519-522. [CrossRef]

20. Kim, K.; Park, C.; Kwon, D.; Kim, D.; Meyyappan, M.; Jeon, S.; Lee, J.-S. Silicon nanowire biosensors for detection of cardiac troponin I (cTnI) with high sensitivity. Biosens. Bioelectron. 2016, 77, 695-701. [CrossRef]

21. Hideshima, S.; Sato, R.; Inoue, S.; Kuroiwa, S.; Osaka, T. Detection of tumor marker in blood serum using antibody-modified field effect transistor with optimized BSA blocking. Sens. Actuators B Chem. 2012, 161, 146-150. [CrossRef]

22. Mulla, M.Y.; Tuccori, E.; Magliulo, M.; Lattanzi, G.; Palazzo, G.; Persaud, K.; Torsi, L. Capacitance-modulated transistor detects odorant binding protein chiral interactions. Nat. Commun. 2015, 6, 6010. [CrossRef]

23. Macchia, E.; Manoli, K.; Holzer, B.; Franco, C.D.; Chittorelli, M.; Torricelli, F.; Alberga, D.; Mangiatordi, G.F.; Palazzo, G.; Scamarcio, G.; et al. Single-molecule detection with a millimetre-sized transistor. Nat. Commun. 2018, 9, 3223. [CrossRef] 
24. Machhia, E.; Sarchina, L.; Picca, R.A.; Manoli, K.; Franco, C.D.; Scamarcio, G.; Torsi, L. Ultra-low HIV-1 p24 detection limits with a bioelectronics sensor. Anal. Bioanal. Chem. 2019, 412, 811-818. [CrossRef]

25. Lin, P.; Luo, X.; Hsing, I.-M.; Yan, F. Organic Electrochemical Transistors Integrated in Flexible Microfluidic Systems and Used for Label-Free DNA Sensing. Adv. Mater. 2011, 23, 4035-4040. [CrossRef]

26. Guo, K.; Wustoni, S.; Koklu, A.; Díaz-Galicia, E.; Moser, M.; Hama, A.; Alqahtani, A.A.; Ahmad, A.N.; Alhamlan, F.S.; Shuaib, M.; et al. Rapid single-molecule detection of COVID-19 and MERS antigens via nanobody-functionalized organic electrochemical transistors. Nat. Biomed. Eng. 2021, 5, 666-677. [CrossRef]

27. Dastan, D.; Banpurkar, A. Solution processable sol-gel derived titania gate dielectric for organic field effect transistors. J. Mater Sci: Mater. Electron. 2017, 28, 3851-3859. [CrossRef]

28. Zhang, Y.; Wu, Z.; Li, K.; Li, X.; Yang, A.; Tong, P.; Chen, H. Allergenicity assessment on thermally processed peanut influenced by extraction and assessment methods. Food Chem. 2019, 281, 130-139. [CrossRef]

29. Köhler, G.; Milstein, C. Continuous cultures of fused cells secreting antibody of predefined specificity. Nature 1975, $256,495-497$. [CrossRef]

30. McKearn, T.J. Cloning of hybridoma cells by limiting dilution in fluid phase. Monocl. Antibod. 1980, $1980,374$.

31. Song, H.N.; Kim, D.H.; Park, S.G.; Lee, M.K.; Paek, S.H.; Woo, E.J. Purification and characterization of Fab fragments with rapid reaction kinetics against myoglobin. Biosci. Biotechnol. Biochem. 2015, 79, 718-724. [CrossRef]

32. Taur, Y.; Ning, T.H. Fundamentals of Modern VLSI Devices, 2nd ed.; Cambridge: New York, NY, USA, 2012 ; pp. 148-203.

33. Shoorideh, K.; Chui, C.O. Optimization of the sensitivity of FET-based biosensors via biasing and surface charge engineering. IEEE Trans. Electron. Dev. 2012, 59, 3104-3110. [CrossRef]

34. Hideshima, S.; Hinou, H.; Ebihara, D.; Sato, R.; Kuroiwa, S.; Nakanishi, T.; Nishimura, S.-I.; Osaka, T. Attomolar detection of influenza A virus hemagglutinin human $\mathrm{H} 1$ and avian $\mathrm{H} 5$ using glycan-blotted field effect transistor biosensor. Anal. Chem. 2013, 85, 5641-5644. [CrossRef]

35. Tajima, N.; Takai, M.; Ishihara, K. Significance of Antibody Orientation Unraveled: Well-Oriented Antibodies Recorded High Binding Affinity. Anal. Chem. 2011, 83, 1969-1976. [CrossRef]

36. Kurganov, B.I.; Lobanov, A.V.; Borisov, I.A.; Reshetilov, A.N. Criterion for Hill equation validaity for description of biosensor calibration curve. Anal. Chim. Acta 2001, 427, 11-19. [CrossRef]

37. Tschmelak, J.; Kumpf, M.; Kappel, N.; Proll, G.; Gauglitz, G. Total internal reflectance fluorescence (TIRF) biosensor for environmental monitoring of testosterone with commercially available immunochemistry: Antibody characterization, assay development and real sample measurements. Talanta 2006, 69, 343-350. [CrossRef]

38. Gao, A.; Lu, N.; Wang, Y.; Li, T. Robust ultrasensitive tunneling-FET biosensor for point-of-care diagnostics. Sci. Rep. 2016, 6, 22554. [CrossRef]

39. Shrivastava, A.; Gupta, B. Methods for the Determination of Limit of Detection and Limit of Quantitation of the Analytical Methods. Chron. Young Sci. 2011, 2, 21-25. [CrossRef]

40. Peeters, M.; Grinsven, B.V.; Cleji, T.J.; Jiménez-Monroy, K.L.; Cornelis, P.; Pérez-Ruiz, E.; Wackers, G.; Thoelen, R.; Ceuninck, W.D.; Lammertyn, J.; et al. Label-free Protein Detection Based on the Heat-Transfer Method-A Case Study with the Peanut Allergen Ara h 1 and Aptamer-Based Synthetic Receptors. ACS Appl. Mater. Interfaces 2015, 7, 10316-10323. [CrossRef]

41. Pollet, J.; Delport, F.; Janssen, K.P.F.; Tran, D.T.; Wouters, J.; Verbiest, T.; Lammertyn, J. Fast and accurate peanut allergen detection with nanobead enhanced optical fiber SPR biosensor. Talanta 2011, 83, 1436-1441. [CrossRef]

42. Alves, R.C.; Pimentel, F.B.; Nouws, H.P.A.; Marques, R.C.B.; González-García, M.B.; Oliveira, M.B.P.P.; Delerue-Matos, C. Detection of Ara $\mathrm{h} 1$ (a major peanut allergen) in food using an electrochemical gold nanoparticle-coated screen-printed immunosensor. Biosens. Bioelectron. 2015, 64, 19-24. [CrossRef]

43. Sobhan, A.; Oh, J.-H.; Park, M.-K.; Kim, S.W.; Park, C.; Lee, J. Assessment of peanut allergen Ara h1 in processed foods using a SWCNTs-based nanobiosensor. Biosci. Biotechnol. Biochem. 2018, 82, 1134-1142. [CrossRef]

44. Zhou, W.-D.; Dastan, D.; Li, J.; Yin, X.-T.; Wang, Q. Discriminable Sensing Response Behavior to Homogeneous Gases Based on $\mathrm{n}-\mathrm{ZnO} / \mathrm{p}-\mathrm{NiO}$ Composites. Nanomaterials 2020, 10, 785. [CrossRef] 